\title{
Detection of adult celiac disease using duodenal screening biopsies over a 30-year period
}

\author{
Hugh James Freeman MD CM FRCPC FACP
}

HJ Freeman. Detection of adult celiac disease using duodenal screening biopsies over a 30-year period. Can J Gastroenterol 2013;27(7):405-408.

BACKGROUND: Serological studies suggest that celiac disease may be present in approximately $0.5 \%$ to $1 \%$ of the North American population. Screening data based on small intestinal biopsy performed during routine endoscopic evaluations are not available.

METHODS: Patients referred between January 1982 and December 2011 for evaluation of gastrointestinal symptoms and requiring elective investigative upper endoscopic evaluation underwent duodenal biopsies to determine whether changes of adult celiac disease were present.

RESULTS: A total of 9665 patients, including 4008 (41.5\%) males and $5657(68.5 \%)$ females, underwent elective endoscopies and duodenal biopsies. Of these, 234 (2.4\%) exhibited changes of celiac disease including 73 males (1.8\%) and 161 females (2.8\%). During the first 20 years, the number of biopsy-positive patients in five-year intervals progressively decreased and, subsequently, during the next 10 years, the number progressively increased.

CONCLUSIONS: Celiac disease is far more common in specialist practice than has been suggested in the evaluation of healthy populations using serological screening studies. Endoscopic duodenal biopsy is an important method of identifying underlying celiac disease and should be routinely considered in all patients undergoing an elective endoscopic evaluation. Noninherited factors, possibly environmental, may play a role in the appearance of biopsy-defined celiac disease and alter detection over time.

Key Words: Adult celiac disease; Celiac disease screening; Endoscopic biopsy; Small bowel biopsy

Celiac disease is believed to affect approximately $0.5 \%$ to $1 \%$ of the population in some European nations and the United States (1-5). Data from Canada are limited and largely derived from pediatric populations (6-9), while estimates for adults in Canada have been largely derived by 'extension' based on serological screening studies performed in the United States (10).

Traditionally, the diagnosis of celiac disease in routine clinical practice has rested on both an initial small intestinal biopsy showing the typical histopathological features of untreated celiac disease followed by improvement on a gluten-free diet. In recent years, serological evaluation has become widely used for screening populations in investigative studies. In addition, serologically based testing has emerged as a case-finding tool for celiac disease in clinical practice. Finally, serological testing has been used as an adjunct to diagnosis in biopsy-defined disease.

While most believe that small intestinal biopsies, rather than serological studies, remain the 'gold standard' for diagnostic evaluation, some experts have reasonably opined that nonperformance of duodenal biopsy during the endoscopic evaluation process may be contributing to failure to diagnose the disease, particularly in North America (11).

\section{La détection de la maladie coeliaque chez l'adulte à l'aide de biopsies de dépistage dans le duodénum, sur une période de 30 ans}

HISTORIQUE : Les études sérologiques laissent supposer que de 0,5\% à $1,0 \%$ de la population nord-américaine serait atteinte de la maladie coliaque. On ne possède pas de données de dépistage fondées sur une biopsie de l'intestin grêle effectuée pendant les évaluations endoscopiques systématiques.

MÉTHODOLOGIE : Les patients aiguillés entre janvier 1982 et décembre 2011 pour faire évaluer des symptômes gastro-intestinaux et ayant besoin d'une évaluation endoscopique non urgente par voie haute ont subi une biopsie du duodénum pour déterminer s'ils présentaient les changements propres à la maladie cœliaque chez l'adulte.

RÉSULTATS : Au total, 9665 patients, soit 4008 hommes (41,5\%) et 5657 femmes $(68,5 \%)$, ont subi des endoscopies non urgentes et des biopsies du duodénum. De ce nombre, 234 (2,4\%), soit 73 hommes $(1,8 \%)$ et 161 femmes $(2,8 \%)$, présentaient les changements liés à la maladie coliaque. Pendant les 20 premières années, le nombre de patients dont la biopsie avait été positive aux intervalles de cinq ans a diminué progressivement, et pendant les dix années suivantes, ce nombre a augmenté progressivement.

CONCLUSIONS : La maladie cœliaque est beaucoup plus courante dans les cabinets de spécialistes que le laissait supposer l'évaluation de populations en santé au moyen d'études de dépistage sérologique. La biopsie du duodénum par endoscopie représente une méthode importante pour dépister une maladie cœliaque sous-jacente et devrait être systématiquement envisagée chez tous les patients qui subissent une évaluation endoscopique non urgente. Des facteurs non congénitaux, peut-être de nature environnementale, peuvent jouer un rôle dans l'apparition de la maladie cœliaque définie par biopsie et en modifier le dépistage au fil du temps.

The present report used the results of small intestinal biopsies obtained during elective endoscopic examinations over a period of 30 years of routine clinical practice at a university teaching centre. Biopsies revealing typical histopathological changes of celiac disease were then enumerated to assess the long-term prevalence in an adult population seeking tertiary specialist care and to determine whether any clear upward or downward trend of the disorder over time was evident.

\section{METHODS}

All patients were referred to the investigating physician in a teaching hospital setting over a 30-year period from January 1982 to December 2011 for an elective upper endoscopic procedure to evaluate one or more of the following symptoms: abdominal pain, heartburn, nausea, vomiting, diarrhea and/or weight loss.

For all endoscopic evaluations, a standard hospital-defined consent was completed before the procedure to include biopsies of the stomach and duodenum. This consent also specified that any information generated from these procedures could be used for quality assurance review, including medical reporting. After an overnight fast, most patients were administered an intravenous sedative and topical xylocaine spray

Department of Medicine (Gastroenterology), University of British Columbia, Vancouver, British Columbia

Correspondence: Dr Hugh James Freeman, Gastroenterology, University of British Columbia Hospital, 2211 Wesbrook Mall, Vancouver,

British Columbia V6T 1W5. Telephone 604-822-7216, fax 604-822-7236, e-mail hugfree@shaw.ca

Received for publication March 4, 2013. Accepted May 6, 2013 


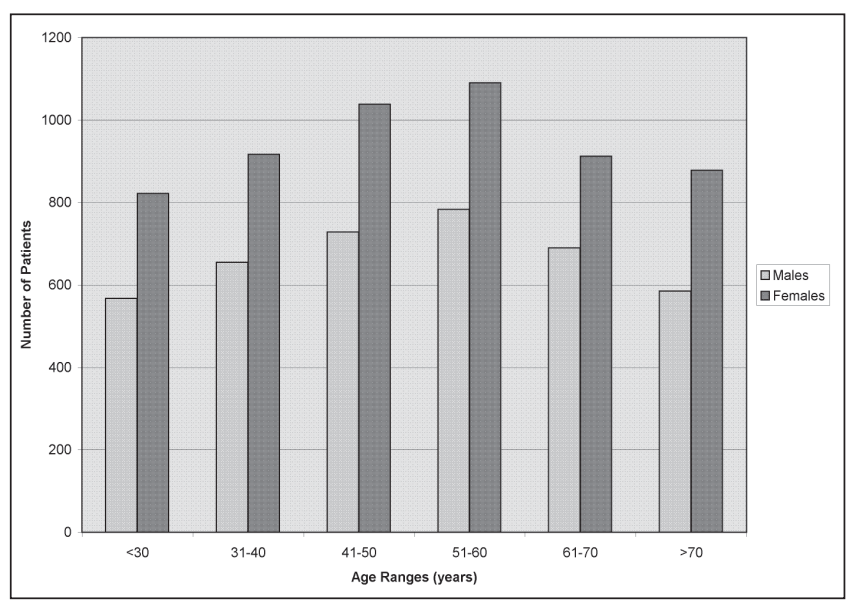

Figure 1) Males $(n=4008)$ and females $(n=5657)$ undergoing an elective endoscopy (with duodenal biopsies) from 1982 to 2011. Note: <30 denotes males and females 30 years of age or younger

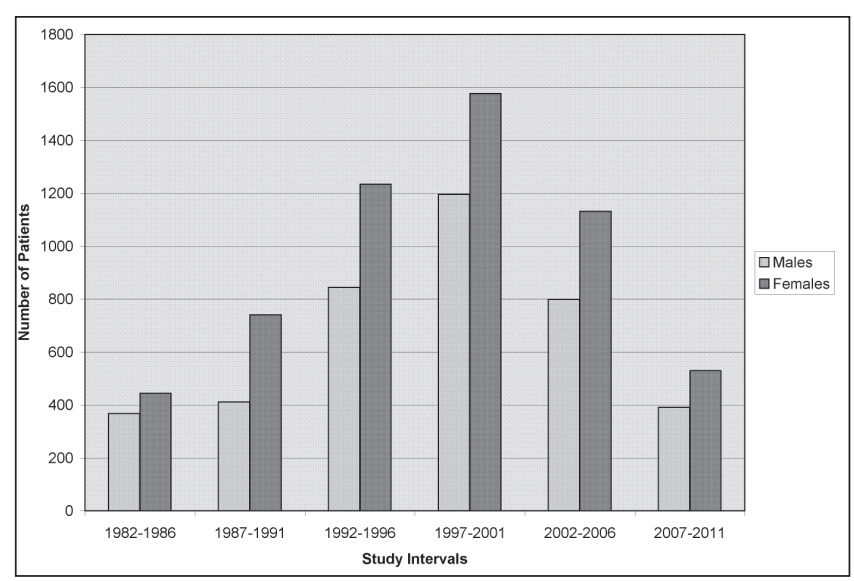

Figure 2) Study intervals (five-year) from 1982 to 2011 for males and females

before the procedure. Some requested that the procedure be performed without sedation. During the course of endoscopic evaluation, biopsies were routinely obtained from the stomach and descending duodenum to confirm visible macroscopic findings, including normal or abnormal appearing mucosa, and exclude any microscopic findings that may account for symptoms. In some patients additional biopsies were also obtained from the duodenal bulb or more distal duodenum.

During the extended course of the 30-year time frame noted, biopsies were performed using Olympus fiberoptic endoscopes (Olympus, Japan) as well as regular and high-definition videoscopes. Biopsies were obtained using regular pinch forceps and placed in fixatives (eg, Bouin's, formalin) after careful orientation on mesh or filter paper with the 'mucosal surface up' in the endoscopy suite. Routine histopathological processing through the biopsy core and biopsy was performed as previously noted (12-14) and interpreted by experienced endoscopic biopsy pathologists. All biopsies reported to be consistent with adult celiac disease were also independently reviewed at that time by the author investigator as a second trained observer of mucosal biopsy material (12-14).

Patients who were referred with previously established biopsy-defined celiac disease for ongoing management, biopsy because of an initially positive serological screening assay for celiac disease (eg, presence of tissue transglutaminase immunoglobulin A antibodies) or a family history of celiac disease were not included in the present evaluation.

Patients with biopsies consistent with celiac disease were evaluated by a dietitian and treated with a gluten-free diet. Compliance with the gluten-free diet was typically monitored by clinical evaluation, although most patients underwent additional biopsies within two years

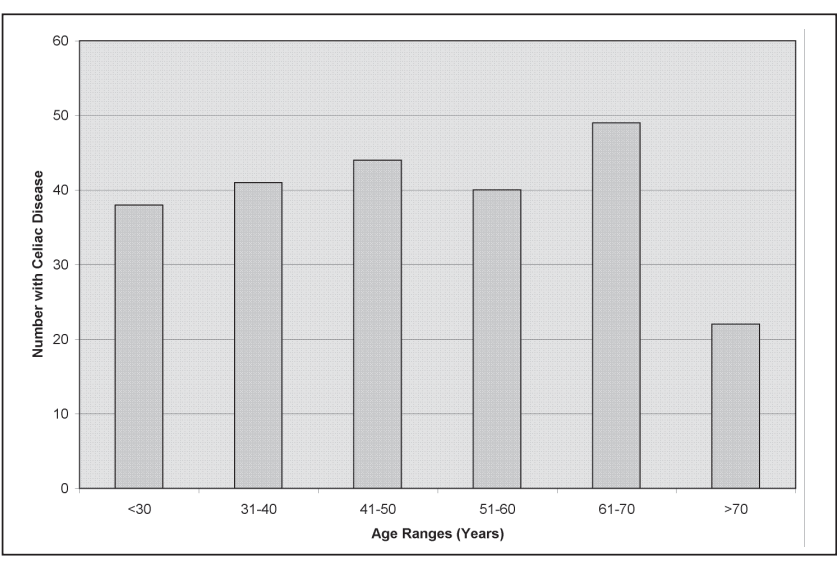

Figure 3) Age ranges with newly-diagnosed celiac disease. Note: $<30$ denotes 30 years of age or younger

from initial evaluation for histological assessment to confirm improved mucosal architecture (14).

Biopsies were considered to be consistent with adult celiac disease only if severe or moderately severe architectural changes were defined (ie, 'crypt hyperplastic villous atrophy', 'total or partial villous atrophy', 'Marsh 3') along with other changes of celiac disease, including intraepithelial lymphocytosis, as noted elsewhere (14). Patients with minimal architectural change or epithelial lymphocytosis alone were not included because previous North American studies involving both children and adults have demonstrated that most patients with this limited severity of histopathological change do not have celiac disease $(15,16)$.

All patient clinical records were retrospectively reviewed and all duodenal biopsy reports retrieved and compiled for the data presented in the present report. Data were compiled annually for males and females and subsequently arbitrarily divided into five-year periods for trend analysis over time. Statistical evaluations were based on $2 \times 2$ contingency tables and calculations using the Fisher's exact test and $\chi^{2}$ analysis.

\section{RESULTS}

Patient study group

During the 30-year course of the present extended evaluation of a single clinical referral practice, 9665 patient chart records that contained duodenal biopsies performed at the University of British Columbia Hospital endoscopy clinic (Vancouver, British Columbia) were stored by the sole author. The entire clinical record for all patients was available for review by the author investigator. These included 4008 (41.5\%) males and 5657 (58.5\%) females of this patient population.

Figure 1 schematically shows adult males and females for each age group during the entire period of clinical evaluation from 1982 to 2011. As shown, females outnumbered males in each age group studied, although the most frequent male and female groups referred for endoscopic studies for both sexes were 51 to 60 years of age.

Figure 2 schematically shows adult males and females for each of the five-year intervals over 30 years of clinical practice. There was a steady increase in the number of patients evaluated by screening duodenal biopsies during the initial 20 years of clinical practice followed by a decline over the next 10 years. As shown, for each five-year study interval, the number of females predominated over the number of males. In fact, the number of females exceeded the number of males evaluated for almost every calendar year from 1982 to 2011, inclusive (except 1984). There were no endoscopic or biopsy complications.

\section{Biopsy-positive patients}

Figure 3 shows the total number of biopsy-positive adults in each age group. Collectively, 234 of 9665 patients $(2.4 \%)$ were positive for 


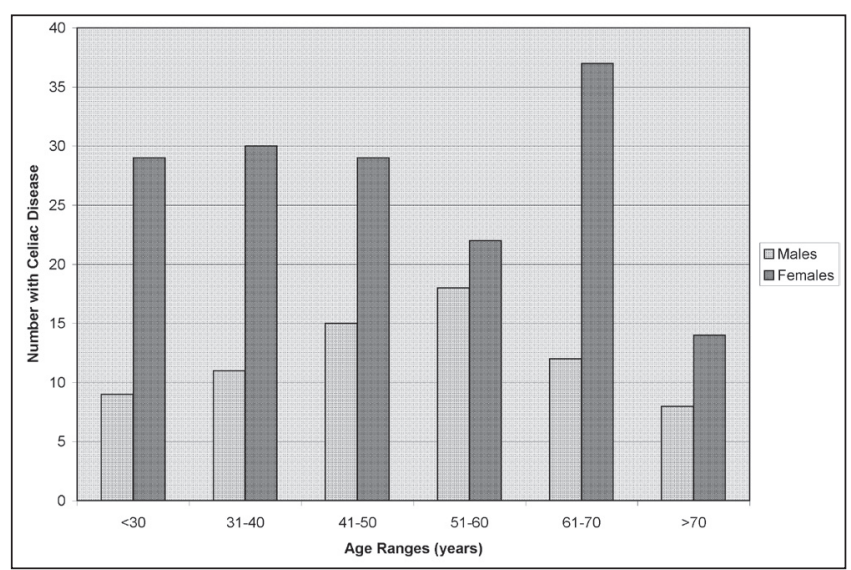

Figure 4) Age ranges of males and females with newly diagnosed celiac disease. Note: $<30$ denotes 30 years of age or younger

newly detected biopsy features of celiac disease. These included 73 of $4008(1.8 \%)$ adult males and 161 of 5657 (2.8\%) adult females. As shown, each age group had similar numbers of patients with biopsy changes consistent with celiac disease, although the absolute number of newly detected celiacs in the most elderly group (ie, $>70$ years of age) was less than all other younger age groups. Figure 4 shows biopsypositive adult males and adult females. For each age group, there were more females than males.

\section{Time-course detection studies}

Figure 5 shows the percentage of biopsy-positive adults for each of six consecutive five-year intervals from 1982 to 2011. Over this 30-year evaluation period, two time trends were evident. There was a significant and progressive fall from $3.9 \%$ to $1.7 \%$ in positive biopsies in each fiveyear interval during the first 20 years $(\mathrm{P}<0.0002)$ of this evaluation, and then a significant and progressive rise over the next 10 years from $1.7 \%$ to $2.7 \%(\mathrm{P}<0.0391)$.

\section{DISCUSSION}

Using endoscopically retrieved duodenal biopsy data, $2.4 \%$ of patients referred for evaluation over the past 30 years and undergoing an elective endoscopic evaluation exhibited changes of celiac disease approximately two to three times higher than results of most reported studies that have based initial suspicion of the disease on serologically based screening methods alone. Only patients with moderate to severe changes in mucosal architecture were included in the present report; therefore, the percentage in this adult population with newly detected histopathological changes of celiac disease may well have been higher. Moreover, asymptomatic patients referred for biopsy solely because of a positive serological assay were not included here because serological testing was not used consistently by physicians referring to our hospital over the past three decades. Finally, even higher rates of biopsy detection (ie, up to $3.9 \%$ ) were observed during some five-year periods. These results provide strong support for a recently published expert evaluation of a United States multiregional endoscopy database spanning a five-year period from 2004 through 2009 (11) emphasizing the conclusion that nonperformance of duodenal biopsy during endoscopy may contribute to underdiagnosis of celiac disease and extends this important hypothesis to actual clinical use in a single referral practice experience over a period of 30 years.

Although endoscopic biopsies were performed in patients referred for elective evaluation of symptoms in the present analysis, the number of screening biopsies performed in each patient was limited, often only to sites in the descending or more distal duodenum. Some studies have recently emphasized that biopsies from the duodenal bulbar region in children $(17,18)$ or adults $(19)$ should also be performed to exclude all patients with biopsy-defined celiac disease, largely owing to the patchy nature of the histological lesions in the proximal small

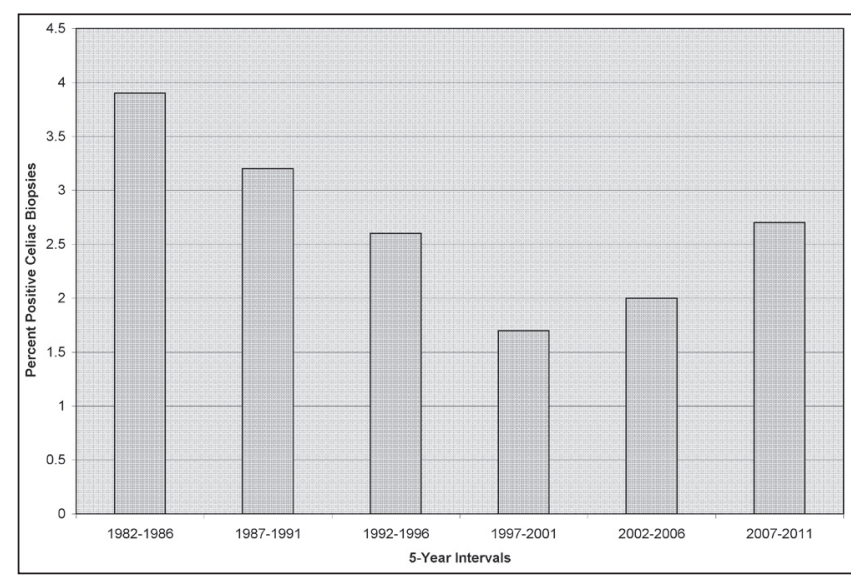

Figure 5) Study intervals (five-year) for biopsy-positive patients with newly diagnosed celiac disease from 1982 to 2011

intestinal mucosa of some patients. In fact, it is conceivable - even likely - that added duodenal bulbar biopsies may have provided a few more 'screen-positive' patients. More specifically, the percentage of positive biopsies from patients may be even higher if added screening biopsies from the duodenal bulbar region had been routinely obtained in all patients. In one recent adult study (19), biopsies from the duodenal bulb were calculated to increase the yield of villous atrophy and detection of newly diagnosed celiac disease by $9 \%$. Although the present study did not compare different biopsy sites within the duodenum in this initial evaluation, experience suggests that villous atrophy in the duodenal bulb alone with completely normal duodenal biopsies from more distal sites is rare. In most newly-diagnosed celiac patients with severe mucosal changes, particularly total villous atrophy that appears to be predominantly localized in the duodenal bulb, biopsies usually demonstrate some histopathological abnormalities, although perhaps only minimal, in more distal duodenal biopsy sites.

The present evaluation also permitted a unique opportunity to explore the hypothesis that celiac disease may be increasing in prevalence, particularly in North America. This apparent increase is likely due, in large part, to increased physician recognition of celiac disease coupled with increased serologically based testing, especially in recent years. Recent studies involving adults and children have also suggested an added hypothesis that a true change in appearance of celiac disease may have occurred, possibly due to other confounding environmental factors $(20,21)$. For example, in young male military recruits, an apparently low prevalence of celiac disease was reported based on testing frozen stored sera collected from 1948 to 1952, compared with more recent control cohorts similar in years of birth or age at sampling (20). The present screening study examining duodenal biopsies provided results over multiple (rather than only two) time periods. In the present evaluation, changes in the percentage of biopsy-positive patients occurred, with a notable reduction from 1982 to 2001, followed by an increasing trend to 2007 to 2011. Genetic factors would not likely change in a relatively short time frame; therefore, these biopsy-based observations appear to extend an earlier serologically based hypothesis (20) in that changes in disease occurrence from year to year may be reflective of a response to environmental or other factors (20). A previous report suggested changes in cereal production and processing, emergence of new or genetically altered forms of wheat, and childhood infections associated with the so-called 'hygiene hypothesis' may be important (20). In addition, physician indications for specialist referral, particularly for elective procedures, could also change over time and alter detection rates. Finally, other factors may deserve further evaluation. In North Americans, these include changes in cigarette consumption and increasing use of oral contraceptives (22-24). An evolving array of medications including nonsteroidal anti-inflammatory drugs (25) and angiotensin II receptor antagonists (26) have been recognized to produce sprue-like intestinal disorders. 
Further studies are needed to explore other nongliadin-related environmental factors that could play a role in the development of adult celiac disease.

\section{SUMMARY}

The present evaluation suggests that celiac disease may be far more common in referral-based specialist practices than has been appreciated. Studies in North America involving healthy populations suggest that serological screening may be an effective method to initiate case detection in clinical practice. Duodenal biopsy, however, is also an important and safe means of identifying underlying celiac disease and should be routinely considered in all patients requiring endoscopic evaluation.

DISCLOSURES: The author has no financial disclosures or conflicts of interest to declare.

ACKNOWLEDGEMENT: The author is grateful to Ms Anna Rooney for her support in completion of this extended study along with generous funding support from the Canadian Celiac Association, Vancouver Chapter.

\section{REFERENCES}

1. Dube C, Rostom A, Sy R, et al. The prevalence of celiac disease in average-risk and at-risk Western European populations:

A systematic review. Gastroenterology 2005;128(4 Suppl 1):S57-67.

2. Fasano A, Berti I, Gerarduzzi T, et al. Prevalence of celiac disease in at-risk and not-at-risk groups in the United States: A large multicenter study. Arch Intern Med 2003;163:286-92.

3. Katz KD, Rashtak S, Lahr BD, et al. Screening for celiac disease in a North American population: Sequential serology and gastrointestinal symptoms. Am J Gastroenterol 2011;106:1333-9.

4. Riddle MS, Murray JA, Porter CK. The incidence and risk of celiac disease in a healthy US adult population. Am J Gastroenterol 2012;107:1248-55.

5. Rubio-Tapia A, Ludvigsson JF, Brantner TL, Murray JA, Everhart JE. The prevalence of celiac disease in the United States. Am J Gastroenterol 2012;107:1538-44.

6. Chartrand LJ, Agulnik J, Vanounou T, Russo PA, Baehler P, Seidman EG. Effectiveness of antigliadin antibodies as a screening test for celiac disease in children. CMAJ 1997;157:527-33.

7. Fitzpatrick KP, Sherman PM, Ipp M, Saunders N, Macarthur C. Screening for celiac disease in children with recurrent abdominal pain. J Pediatr Gastroenterol Nutr 2001;33:250-2.

8. Chan AW, Butzner JD, McKenna R, Fritzler MJ. Tissue transglutaminase enzyme-linked immunosorbent assay as a screening test for celiac disease in pediatric patients. Pediatrics 2001;107:E8.
9. Rashid M, Cranney A, Zarkadas M, et al. Celiac disease: Evaluation of the diagnosis and dietary compliance in Canadian children. Pediatrics 2005;116:e754-9.

10. Fedorak RN, Switzer CM, Bridges RJ. Celiac disease in Canada. Incidence, prevalence, and direct and indirect economic impact. Can J Gastroenterol 2012;26:350-2.

11. Lebwohl B, Tennyson CA, Holub JL, Lieberman DA, Neugut AI, Green PH. Sex and racial disparities in duodenal biopsy to evaluate for celiac disease. Gastrointest Endosc 2012;76:779-85.

12. Perera D, Weinstein WM, Rubin CE. Small intestinal biopsy. Hum Pathol 1975;6:157-217.

13. Lewin KJ, Riddell RH, Weinstein WM. Small bowel mucosal disease. In: Gastrointestinal Pathology and Its Clinical Implications, vol 2. New York: Igaku-Shoin, 1992:792-811.

14. Freeman HJ. Small intestinal mucosal biopsy for investigation of diarrhea and malabsorption in adults. Gastrointest Clin North Am 2000;10:739-53.

15. Schmidt E, Smyrk TC, Faubion WA, Oxentenko AS. Duodenal intraepithelial lymphocytosis with normal villous architecture in pediatric patients, 2000-2009: The Mayo Clinic experience. J Pediatr Gastroenterol Nutr 2012 Jul 9 (Epub ahead of print).

16. Kakar S, Nehra V, Murray JA, Dayharsh GA, Burgart LJ. Significance of intraepithelial lymphocytosis in small bowel biopsy samples with normal mucosal architecture. Am J Gastroenterol 2003;98:2027-33.

17. Ravelli A, Bolognini S, Gambarotti M, Villanacci V. Variability of histologic lesions in relation to biopsy site in gluten-sensitive enteropathy. Am J Gastroenterol 2005;100:177-85.

18. Ravelli A, Villanacci V, Monfredini C, Martinazzi S, Grassi V, Manenti S. How patchy is patchy villous atrophy? Distribution pattern of histological lesions in the duodenum of children with celiac disease. Am J Gastroenterol 2010;105:2103-10.

19. Evans KE, Aziz I, Cross SS, et al. A prospective study of duodenal bulb biopsy in newly diagnosed and established adult celiac disease. Am J Gastroenterol 2011;106:1837-42.

20. Rubio-Tapia A, Kyle RA, Kaplan EL, et al. Increased prevalence and mortality in undiagnosed celiac disease. Gastroenterology 2009;137:88-93.

21. Lohi S, Mustalahti K, Kaukinen K, et al. Increasing prevalence of coeliac disease over time. Aliment Pharmacol Ther 2007;26:1217-25.

22. Snook JA, Dwyer L, Lee-Elliott C, Khan S, Wheeler DW, Nicholas DS. Adult coeliac disease and cigarette smoking. Gut 1996;39:60-2.

23. Vazquez H, Smecuol E, Flores D, et al. Relation between cigarette smoking and celiac disease: Evidence from a case control study. Am J Gastroenterol 2001;96:798-802.

24. Austin AS, Logan RF, Thomason K, Holmes GK. Cigarette smoking and adult coeliac disease. Scand J Gastroenterol 2002;37:978-82.

25. Freeman HJ. Sulindac-associated small bowel lesion. J Clin Gastroenterol 1986;8:569-71.

26. Rubio-Tapia A, Herman ML, Ludvigsson JF, et al. Severe spruelike enteropathy associated with olmesartan. Mayo Clin Proc 2012;87:732-8. 


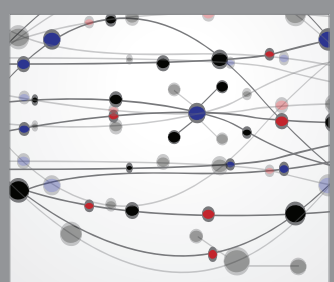

The Scientific World Journal
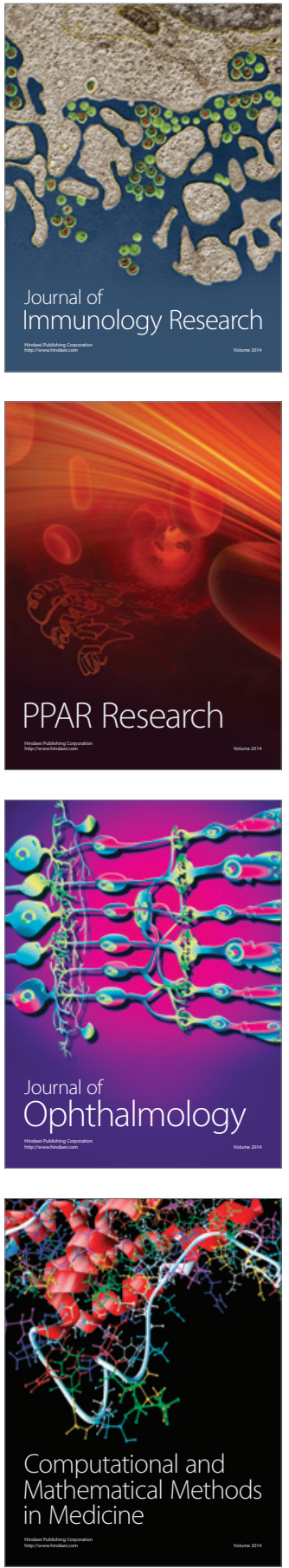

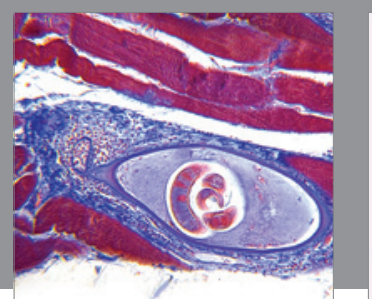

Gastroenterology Research and Practice

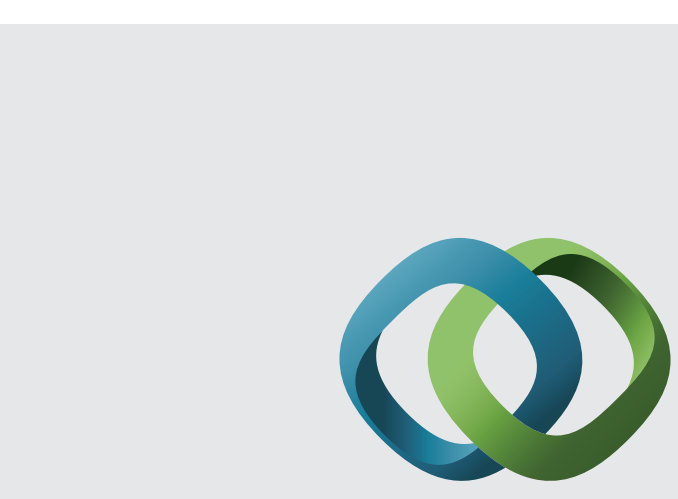

\section{Hindawi}

Submit your manuscripts at

http://www.hindawi.com
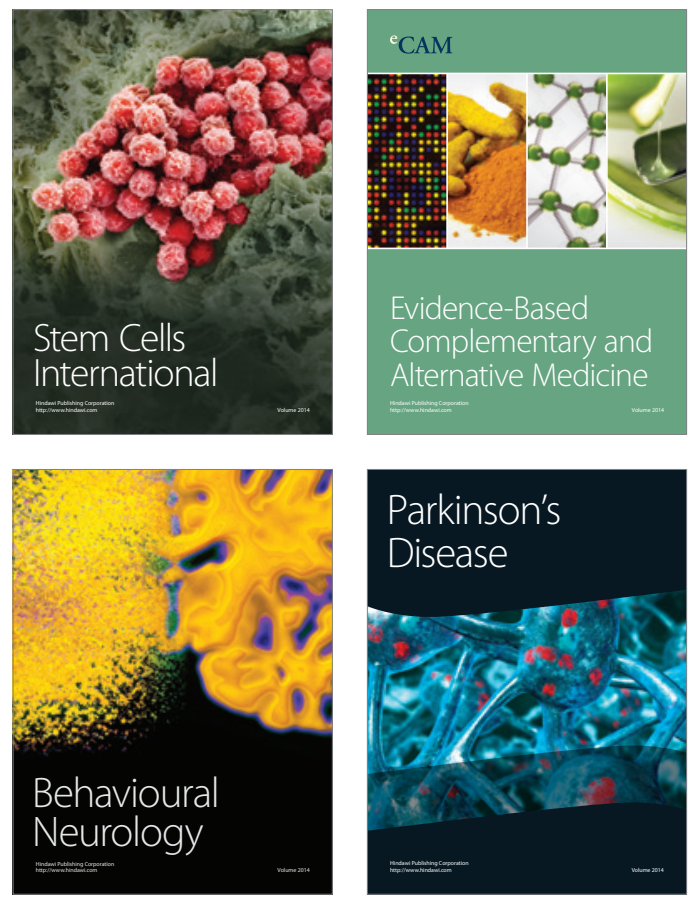
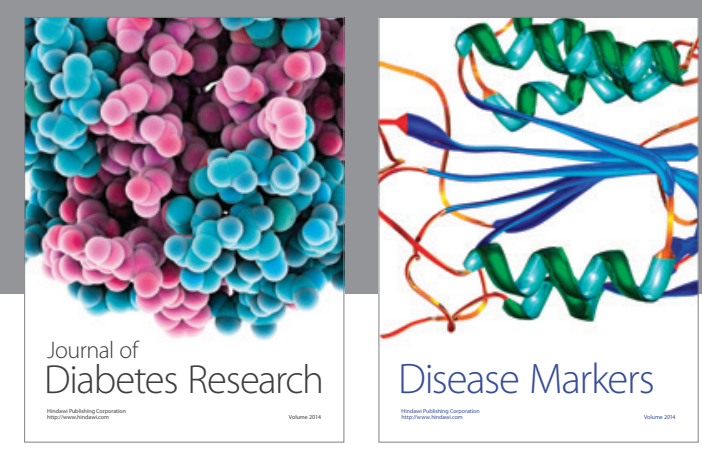

Disease Markers
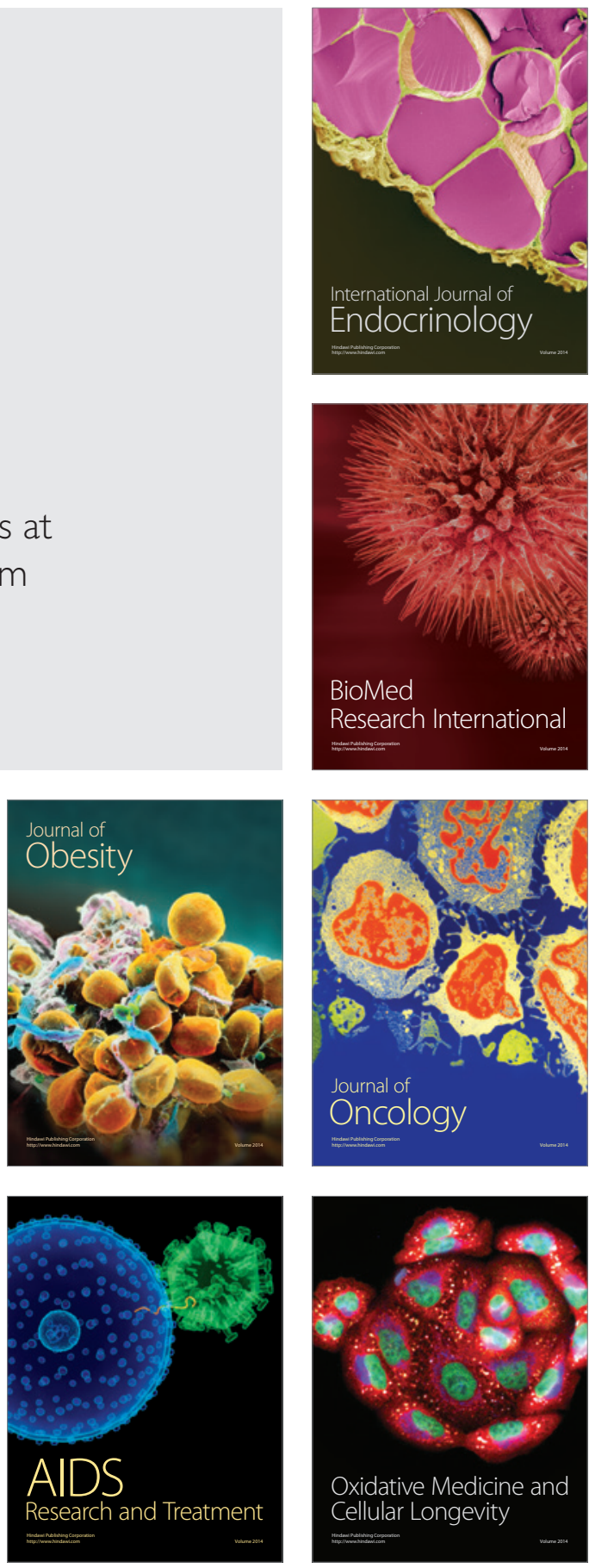